\title{
RESULTADOS ELECTORALES Y ORIENTACIÓN DEL VOTO EN LOS COMICIOS MUNICIPALES DE 1995
}

\author{
Irene Delgado Sotillos \\ Universidad Nacional de Educación a Distancia (UNED) \\ E-mail: Idelgado@poli.uned.es
}

\begin{abstract}
RESUMEN
El presente artículo pretende hacer un balance de las elecciones municipales de 1995 examinando desde dos perspectivas analíticas sus principales elementos. Se organiza el trabajo partiendo de un análisis agregado que explora los niveles de movilización, orientación del voto municipal y preferencias de los electores. Posteriormente, mediante técnicas multivariables, se determinan los elementos más influyentes en las opciones de voto a los dos partidos mayoritarios. La nacionalización de la convocatoria municipal y la fuerte partidificación son elementos que confirman la hipótesis de la particularidad de estas elecciones municipales con un alto contenido de "primarias». Ello condiciona sus resultados, que además han estado influidos por su ubicación en el calendario electoral, el clima de descontento político nacional y las posibilidades de alternancia política.
\end{abstract}

\section{INTRODUCCIÓN: LAS ELECCIONES MUNICIPALES DE 1995 EN EL CONTEXTO POLÍTICO ESPAÑOL}

El 28 de mayo de 1995 se celebraron las quintas elecciones municipales del período democrático. La particularidad de estas elecciones viene conferida por estar convocadas en un contexto dominado por la crisis política en la arena nacional (Pallarés, 1996: 149; Delgado, 1997). La campaña electoral reflejó esta realidad nacional, por lo que en los discursos prevalecieron los temas estatales 
sobre los estrictamente locales. La lucha por el control del poder nacional entre el PP y el PSOE y el significado nacional que podían tener los resultados de esta convocatoria subnacional convirtieron a estas elecciones en un acontecimiento político con escasos componentes municipales. Esta dosis de nacionalización municipal ${ }^{1}$ quedó asegurada por su ubicación en el calendario electoral: las precedieron las elecciones legislativas de 1993 y la convocatoria europea de 1994. En las primeras, los electores percibieron al PP como una fuerza alternativa al partido del gobierno, influidos por un clima de alta competitividad que tuvo como resultado una situación de "cuasi-equilibrio" entre el PSOE y el PP, sin precedentes en la etapa democrática española. Posteriormente, las elecciones europeas de 1994 fueron la primera ocasión en que el PP triunfó imponiéndose sobre el PSOE. Obtiene de forma mayoritaria el control político en unas elecciones subnacionales con un alto contenido «nacional». Estas dos experiencias sirvieron, junto con la crisis interna del PSOE y los temas de corrupción y financiación ilegal del Partido Socialista, para que las elecciones municipales de 1995 ofrecieran de nuevo un escenario favorable para el cambio de orientaciones partidistas entre el electorado.

Lógicamente, en el análisis de las elecciones municipales y en la interpretación de sus resultados va a influir de forma significativa el contexto político nacional. Actuar al margen de la esfera política nacional centrándose en un análisis estrictamente municipal es una tarea complicada por la especificidad intrínseca de las elecciones municipales. Su grado de interconexión con el escenario nacional difumina las fronteras locales y permite la entrada de influencias externas en el entorno municipal, predominando en un número significativo de las preferencias electorales un componente nacional que reduce las diferencias regionales y tiende a la homogeneidad del proceso electoral. En este sentido los aspectos nacionales de la política adquieren más importancia, en detrimento de los elementos locales, sustituyendo, en muchas dimensiones, la política nacional a la política local (Caramani, 1994). La captación de la atención pública hacia asuntos de carácter nacional y el incremento de la dependencia respecto a un centro nacional confirma la reducción del alcance de los problemas locales y tiende a globalizarlos dentro del sistema político. Además, la creciente partidificación del escenario municipal ${ }^{2}$ convierte a éste en una arena controlada por unos protagonistas con escaso interés por la política municipal, lo que favorece el traspaso de la política nacional al ámbito municipal y la subordinación de los intereses locales (Brugué y Gomá, 1988: 17)³. En

${ }^{1}$ La nacionalización así entendida se refiere a que cada vez los comicios municipales se parecen más a las elecciones legislativas, en términos de debate, actores políticos y, sobre todo, en los resultados electorales.

2 Por partidificación entendemos una elevada presencia e influencia de actores políticos en el escenario local.

${ }^{3}$ Estos autores definen las premisas básicas de esta formulación en torno a: $1 .^{\circ}$ ) el dominio de los intereses nacionales sobre los locales; $2 .^{\circ}$ ) la nacionalización y homogeneización de la política local, que la vacía de su contenido específico; $3 .^{\circ}$ ) la existencia de partidos políticos fuertes y altamente jerarquizados. 
términos generales, las elecciones municipales se convierten en acontecimientos que los partidos políticos utilizan para impulsar la nacionalización, siendo ocasiones apropiadas - por su ubicación en el calendario electoral- para medir el clima político nacional y el grado de satisfacción con el gobierno central.

En las elecciones municipales de 1995 se aúnan estos requisitos: estuvieron ubicadas en un momento político que tradujo ese clima de descontento, resultando un comportamiento electoral influido por esa realidad nacional más compleja, y las consecuencias aportaron un ingrediente con carácter «extraordinario» a la vida política española ${ }^{4}$. Se podría considerar que también las elecciones municipales de 1991 — convocadas a una distancia suficiente de las elecciones legislativas - se convirtieron en unas "primarias» que ponían en tela de juicio la política del gobierno nacional. Sin embargo, se carecía en aquel momento de un referente de cambio político como el que ocurrió en 1993 con un gobierno nacional de apoyos y con la victoria en 1994 del partido de la oposición parlamentaria. Está claro que las elecciones de 1991 podrían ser consideradas primarias de las elecciones generales de 1993, pero su carácter difiere de las elecciones de 1995 por cuanto existía en éstas ya una experiencia de cambio del sistema partidista y de las orientaciones de los electores —en una convocatoria subnacional-, que se tradujo en un aumento de la movilización municipal, a diferencia del abstencionismo de 1991. Estas elecciones serían, en todo caso, dos formas divergentes de interpretar unos comicios locales a través de las coordenadas nacionales.

Sin caer en el abuso de esta perspectiva, vamos a tratar de delimitar cuál fue el contenido y el significado que tuvieron estas elecciones municipales de mayo de 1995, teniendo presente que la configuración del mapa municipal español delimita unos comportamientos electorales diferenciados y la configuración del sistema de partidos no se asemeja al nacional por la presencia de actores, que en este escenario encuentran el medio favorable para desarrollarse $(\text { Delgado, 1996) })^{5}$. No se pretende una aproximación a la dinámica de las políticas locales, sino que se trata de aportar algunas notas sobre el comportamiento de los electores en los pasados comicios municipales, dejando para posteriores estudios su interpretación dentro del comportamiento electoral de los españoles y escapando también a su ubicación en el debate comparado. Nuestro análisis intentará destacar algunas de las líneas que guiaron las orientaciones de los ciudadanos en las elecciones municipales, aun conociendo que esta complicada "galaxia local» conlleva dificultades analíticas, teóricas e incluso terminológicas (Botella, 1992).

${ }^{4}$ Si se sostiene esta hipótesis, las consecuencias de las elecciones municipales de 1995 tuvieron cierta incidencia en los resultados de la convocatoria legislativa de 1996 y pueden considerarse como una primera prueba que superó el PP para alcanzar la mayoría a nivel nacional.

${ }^{5} \mathrm{Ha}$ de tenerse en cuenta que la distribución geográfica de los más de 8.000 municipios españoles es muy desigual, por lo que hablamos de un elevado número de convocatorias electorales y la configuración de otros tantos sistemas de partidos. 


\section{LA COYUNTURA POLÍTICA: LA PARTICIPACIÓN Y LA ORIENTACIÓN DEL VOTO MUNICIPAL}

\section{Los niveles de participación electoral municipal}

El porcentaje de participación en las elecciones municipales de 1995 fue del 69,7 por 100 , el mayor de toda la serie electoral municipal ${ }^{6}$, superando ligeramente los niveles de participación de las elecciones de 1987. Si bien los primeros comicios municipales de 1979 no despertaron el entusiasmo esperado por las fuerzas políticas por haberse convocado un mes antes elecciones legislativas, y en las elecciones de 1983 se tenía presente el reciente efecto movilizador de las elecciones de 1982, las elecciones de 1987, al celebrarse simultáneamente con las elecciones a los trece Parlamentos autonómicos «no históricos» y las primeras elecciones al Parlamento Europeo, fueron elementos que despertaron el interés de los españoles. Por vez primera, en 1987 se aunaban en un mismo día elecciones de segundo orden y la participación alcanzó la cifra de 69,1 por 100 . Las elecciones municipales convocadas cuatro años más tarde, en mayo de 1991, no lograron superar ni siquiera mantener esas cifras; más bien al contrario, la movilización fue seis puntos menor (62,8 por 100). Si hasta ese momento, las elecciones de 1987 alcanzaban unas cotas cercanas a la participación en las elecciones legislativas de 1979 y de 1989, la movilización de las elecciones municipales de 1995 cambiaron la tendencia de 1991, equiparándose a los índices de 1987. Sin embargo, el significado de ambos resultados tiene interpretaciones diferentes. Las elecciones de 1987 supusieron un "premio» y dieron continuidad a la labor municipal llevada a cabo en la mayoría de los municipios españoles, mientras que la movilización de 1995 contenía una dosis de "castigo» al gobierno nacional por los escándalos políticos iniciados en el escenario nacional en 1990, si bien ya se reflejó en los resultados de los grandes municipios en 1991 (Delgado y López Nieto, 1997: 251). Las elecciones municipales de 1991 en las zonas urbanas ya fueron los primeros testigos del cambio que ocurrió en 1995 y que se extendió al resto de los municipios. Entonces, al no ofrecerse todavía el PP como alternativa fuerte, la mayor parte de los electores se refugiaron en la abstención. Mientras, los cambios acontecidos durante el transcurso de esos cuatro años a nivel nacional ofrecieron un panorama del que el PP salía fortalecido.

La interpretación de la movilización de 1995 está, por tanto, condicionada por una serie de variables exógenas al propio proceso que rige a unas elecciones de segundo orden (Reif, 1985: 24) y pueden ser consideradas, en mayor medida que las de 1991 — por sus índices de movilización y por sus resultados electorales-, desde la perspectiva de una convocatoria con tintes de "barómetro" sobre la situación política nacional (Game, 1981: 63; Corbetta y Parisi, 1985:

${ }^{6}$ Se reconoce por primera vez en estas elecciones municipales el derecho de sufragio activo a ciudadanos no españoles residentes en España. Y, en virtud de los tratados de reciprocidad con Suecia, Holanda, Noruega y Dinamarca, se incluye en el censo electoral a un porcentaje nuevo de electores. 
73; Curtice y Payne, 1991: 6). En ellas influyeron los resultados de las elecciones legislativas de 1993, adelantadas por el PSOE, que proyectaron una posibilidad de cambio, confirmando al PP como una opción política, factor que claramente movilizó al electorado en 1995. Este ambiente también fue percibido en las elecciones europeas de 1994, donde la participación fue significativamente mayor a la de 1989, obteniendo el PP por primera vez una victoria a nivel nacional.

\section{GRÁFICO 1}

\section{Participación electoral en comicios municipales}

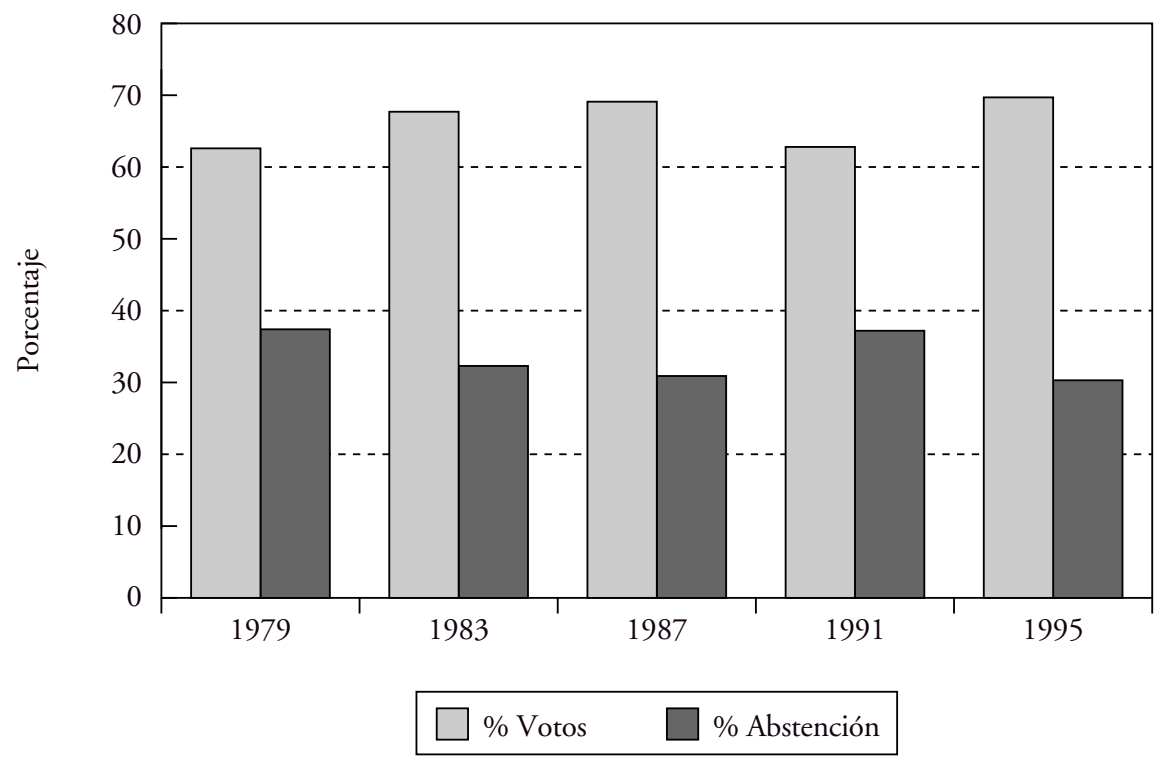

Fuente: Elaboración propia. Datos del Ministerio de Justicia e Interior.

El aumento de la participación registrado en 1995 no se repartió de manera homogénea por los municipios españoles. Quienes en mayor medida se movilizaron fueron los electores de las grandes ciudades y de las zonas más rurales, confirmando el cambio que iniciaron los municipios urbanos en las elecciones de 1991 (Vallés y Sánchez, 1994; Delgado, 1996). Aunque estas grandes poblaciones no alcanzan la participación media nacional, la específica sensibilidad de estos núcleos a los acontecimientos políticos nacionales —en la que tuvieron decisiva influencia los medios de comunicación al facilitar la permeabilidad de los factores coyunturales - , fue el factor que favoreció la movilización electoral. Por otro lado, aunque los pequeños municipios establezcan una conexión más personal y 
directa con el ámbito local, tampoco escaparon a estos condicionantes nacionales y el electorado participó en mayor medida en estas elecciones municipales que en las de 1991. En definitiva, fue la incidencia de factores exógenos a la naturaleza política municipal la que alentó a los ciudadanos a expresar sus preferencias electorales de una manera distinta a la que hasta entonces les había guiado ${ }^{7}$.

\section{CUADRO 1}

Participación en las elecciones municipales de 1991 y 1995 por tramos de población

\begin{tabular}{|c|c|c|c|}
\hline \multirow[b]{2}{*}{ Tamaño de población } & \multicolumn{3}{|c|}{ Participación electoral municipal } \\
\hline & 1991 & 1995 & Variación 91/95 \\
\hline 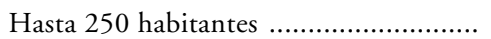 & 75,12 & 80,53 & $+5,41$ \\
\hline 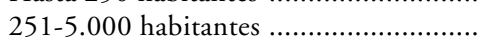 & 76,17 & 79,09 & $+2,93$ \\
\hline 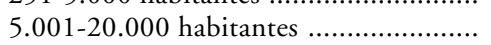 & 68,97 & 72,33 & $+3,36$ \\
\hline 20.001-50.000 habitantes ....................... & 62,06 & 68,51 & $+6,45$ \\
\hline 50.001-100.00 habitantes ...................... & 57,29 & 65,25 & $+7,96$ \\
\hline $100.001-400.000$ habitantes ................... & 54,96 & 64,41 & $+9,45$ \\
\hline 400.001-1 millón habitantes ................... & 56,48 & 67,33 & $+10,85$ \\
\hline Más 1 millón habitantes ........................ & 58,84 & 69,40 & $+11,36$ \\
\hline
\end{tabular}

FUENTE: Delgado (1996).

También la distribución de la participación electoral por CC.AA. muestra cambios respecto al comportamiento en las elecciones municipales precedentes. El fenómeno participativo de esta convocatoria afecta a todos estos entes territoriales y aumenta el número de CC.AA. cuyos niveles de participación superan el 70 por 100: pasan de ser dos en 1991 a nueve en 1995. Este fenómeno participativo se percibe con fuerza en todo el mapa electoral, extendiéndose por las zonas centrales y contagiando a CC.AA. costeras «abstencionistas" por excelencia, como Galicia, Canarias, Cataluña y País Vasco. Aunque estas Comunidades habían mantenido una marcada tendencia hacia la desmovilización durante todas las anteriores convocatorias municipales, en 1995 incrementan su nivel de participación, uniéndose a esa tendencia generalizada en el resto del territorio español. De esta manera, la diferencia ente la comunidad más participativa —Castilla-La Mancha_ y la menos - Baleares — alcanza unas proporciones significativamente más reducidas que en elecciones anteriores (un 15,2 por 100).

El reparto geográfico es inversamente proporcional al tamaño de los municipios; de ahí que se recurra a los análisis por tramos de población como medida más apropiada para analizar la realidad electoral municipal española. Numerosos trabajos coinciden en señalar que la influencia del tamaño de población es una variable sociológica con gran fuerza explicativa en los efectos movilizadores y en las preferencias de los ciudadanos (Milbrath, 1965 y 1981; Karning y Walter, 1983). 


\section{CUADRO 2}

Participación electoral municipal por Comunidades Autónomas, 1991-1995

\begin{tabular}{|c|c|c|c|}
\hline & \multicolumn{3}{|c|}{ Niveles de participación electoral } \\
\hline & 1991 & 1995 & Variación 91/95 \\
\hline 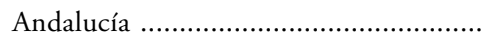 & 61,1 & 68,4 & $+7,4$ \\
\hline 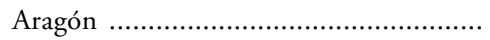 & 64,4 & 71,1 & $+6,7$ \\
\hline 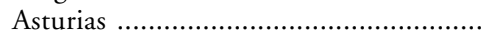 & 58,7 & 68,7 & $+10,0$ \\
\hline 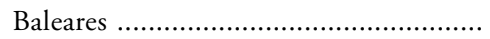 & 61,9 & 63,7 & $+3,5$ \\
\hline 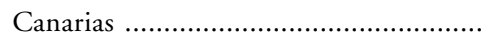 & 61,9 & 64,3 & $+2,4$ \\
\hline 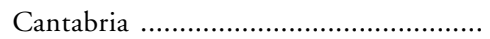 & 71,8 & 73,7 & $+0,8$ \\
\hline Castilla-La Mancha ….............................. & 72,9 & 78,9 & $+6,0$ \\
\hline Castilla y León & 67,9 & 73,7 & $+5,8$ \\
\hline 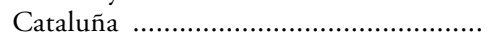 & 57,8 & 64,7 & $+6,9$ \\
\hline Comunidad Valenciana ............................ & 69,3 & 76,1 & $+6,7$ \\
\hline 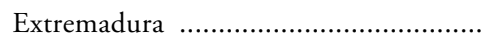 & 71,7 & 78,3 & $+6,6$ \\
\hline Galicia & 62,1 & 67,4 & $+5,3$ \\
\hline Madrid …...................................... & 58,9 & 70,5 & $+11,6$ \\
\hline Murcia & 67,3 & 75,4 & $+8,1$ \\
\hline Navarra & 66,5 & 68,7 & $+2,2$ \\
\hline 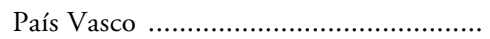 & 59,1 & 64,3 & $+5,1$ \\
\hline 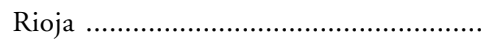 & 69,7 & 76,0 & $+8,1$ \\
\hline
\end{tabular}

FuENTE: Elaboración propia. Datos del Ministerio de Justicia e Interior.

\section{LAS PREFERENCIAS ELECTORALES MUNICIPALES}

El dominio de los partidos políticos nacionales en la política local es indudable. Las fuerzas políticas nacionales se convierten en los principales agentes de nacionalización de la política local como resultado del apoyo que reciben de los electores municipales, un respaldo superior al que tienen otros actores locales o regionales. El reducido interés que tienen los actores nacionales por la política local puede vaciarla de su contenido municipal y, de esta forma, homogeneizar la dinámica política. Sin embargo, ante esta afirmación se deben tomar precauciones porque la respuesta a los elementos nacionales es desigual de unas zonas geográficas a otras, en función de los tamaños de los distritos y de la influencia que tengan los rasgos locales, que son en definitiva los neutralizadores de esa reacción nacional. También el tipo de respuesta difiere según el arraigo de los partidos nacionales y locales en la arena municipal, y de los cleavages que operen en el escenario de competición (Butler y Stokes, 1974).

La estructura municipal española ofrece ciertas dificultades a los grandes partidos para presentar candidaturas, concretamente en los municipios pequeños, dada la debilidad de las organizaciones partidistas y la heterogeneidad que 
domina a las estructuras internas de los mismos ${ }^{8}$. A pesar de ello, no hay duda de que los resultados electorales ofrecen pruebas para hablar del predominio de los partidos nacionales en la política local y confirmar que su penetración - ya «estable» con el paso del tiempo- afecta a la dinámica partidista municipal (Gyford, 1980; Carrillo, 1989; Thomsen, 1992; Deschouwer, 1994). Un indicador de este proceso es el número de candidaturas que los partidos de ámbito nacional presentan en las elecciones municipales: éstas alcanzan el 75 por 100, $y$, consecuentemente, relegan a un plano inferior la presencia de partidos regionalistas y de independientes (Delgado, 1996: 425). Esta escasa fuerza de las formaciones partidistas menores, quienes representarían en sí de forma más específica los valores locales, contrastaría con la inclusión de asuntos nacionales en el discurso local por parte de las formaciones políticas con presencia en el ámbito nacional. Aunque estos grandes partidos que compiten en el escenario municipal introduzcan en sus programas elementos propios de esta esfera política subnacional, éstos serían lógicamente menores y sometidos a cuestiones que mantienen en todo momento el referente nacional ${ }^{9}$. Es en este ámbito acaparado por los grandes partidos donde persiste la debilidad de los pequeños partidos $y$, aunque sin desaparecer completamente, su lucha por obtener representación local ha variado con el paso del tiempo, observándose, al igual que en otros países europeos, una tendencia decreciente (Stewart, 1983; Capo, 1991; Delgado, 1997). La disminución de la presencia de las candidaturas de independientes contribuye a aumentar la homogeneidad entre las fuerzas políticas y a reducir la diversidad del juego político (Gyford, Leach y Game, 1989: 22).

La evolución e implantación de fuerzas políticas nacionales alcanza su máximo referente en las elecciones de 1995: todavía hay 806.403 electores —el 3,64 por 100 - que confían su voto a listas de independientes, y sus 4.296 concejales - el 6,54 por 100 del total nacional- obtienen representación en ayuntamientos de pequeñas poblaciones. Estos datos confirman que, a pesar de esta realidad, no se debe olvidar que las elecciones municipales son acontecimientos locales y de esta forma son percibidos por algunos electores, quienes votan de manera diferente respecto a otras elecciones por estar más determinados por circunstancias locales (Wilson y Game, 1994: 184), aunque en definitiva este grupo es el menor cuantitativamente hablando. Si siguiéramos esta lógica deberíamos hablar de cierta inconsistencia nacional y se convertiría la arena municipal en un espacio en el que dominara un componente generador de un nuevo localismo (Brugué y Gomá, 1998: 19). Desde esta perspectiva, y teniendo presente la configuración municipal española, el ingrediente de nacionalización no afectaría a un número relativamente alto de municipios; en cambio, sí a un significativo número de votantes. Pero aunque sostengamos como hipó-

${ }^{8}$ Esto fue especialmente importante en las elecciones municipales de 1979 ante la nueva etapa política que se iniciaba en España (Delgado, 1997).

9 No es éste el momento para profundizar en los discursos de las campañas electorales de estos comicios que consideramos una alternativa determinante para iluminar un poco más esta empañada realidad municipal. 
tesis la presencia de rasgos locales, las especificidades coyunturales de las convocatorias tienen una influencia que se superpone a la naturaleza municipal de las elecciones. Ese creciente localismo, en el que el ámbito local recupera relevancia y lo que en él se realiza tiene una explicación desde una óptica local, parece atribuirse únicamente a las políticas, y no es un instrumento analítico para el comportamiento electoral en todas sus dimensiones.

Concretamente en las elecciones municipales de 1995, los tamaños de municipios donde se analicen los resultados de la competición partidista permiten detectar la influencia de los rasgos nacionales y el nivel de componente municipal. La presencia de listas de independientes en los municipios rurales —circunscripciones hasta 20.000 habitantes, que representan el 96,6 por 100 del total de municipios, donde vive el 36,9 por 100 de la población españolaes todavía importante. Aunque respecto a 1991 la especificidad de esta convocatoria justifica la disminución de estas fuerzas menores en todos los municipios, es considerable esta pérdida en poblaciones de más de 20.000 habitantes. Éste es un síntoma de que factores nacionales han predominado en la orientación de los votantes con mayor fuerza que en las elecciones municipales anteriores. Aunque los independientes todavía obtienen representación, su presencia confirma la tendencia decreciente ya iniciada en años anteriores.

\section{GRÁFICO 2}

Distribución de votos de las fuerzas de independientes por tramos de población en las elecciones municipales de 1991 y 1995

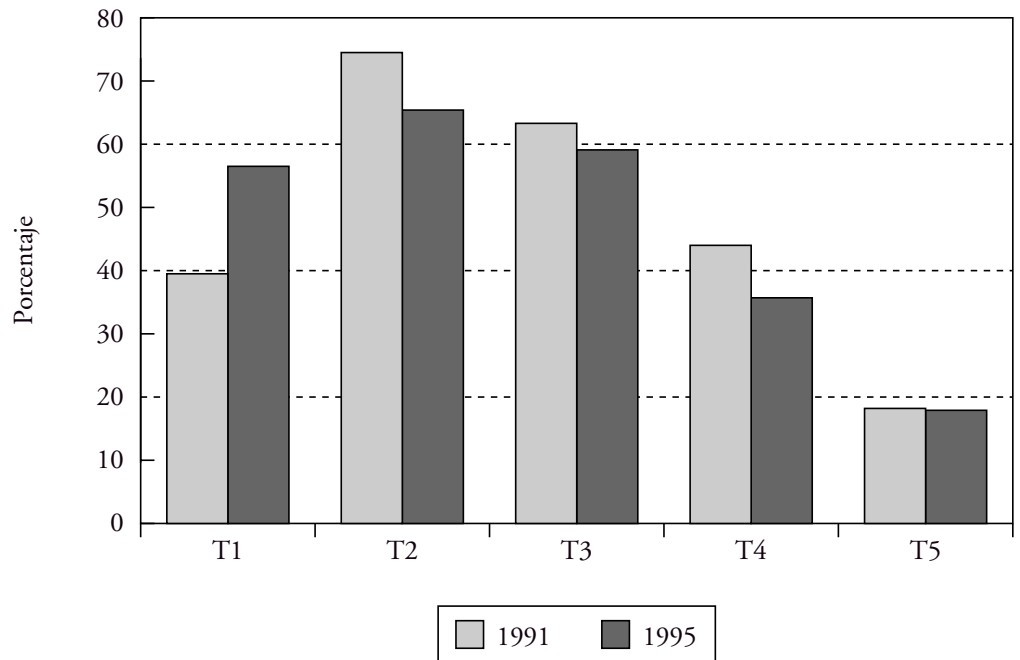

T1: Hasta 250 habitantes. T2: De 251 a 5.000 habitantes. T3: De 5.001 a 20.000 habitantes. T4: De 20.001 a 50.000 habitantes. T5: Más de 50.000 habitantes.

Fuente: Elaboración propia. Datos del Ministerio de Justicia e Interior. 
Las elecciones de 1995 supusieron un cambio en los apoyos electorales. Si bien se preanunció en 1991, especialmente en las capitales de provincia, no culmina hasta estos últimos comicios. En esta ocasión el PP es la fuerza vencedora de la convocatoria municipal e incrementa en más de tres millones los votantes de las elecciones anteriores. Los vencidos en esta competición electoral fueron el CDS, que pierde 667.748 votos, y el PSOE. Este último partido sufre un gran retroceso $y$, aunque es la segunda fuerza política municipal, se queda a una distancia de 4,5 puntos del PP. La tercera fuerza, IU, lejos de ambos, logra avanzar 3 puntos respecto a 1991 y se sitúa a 23,6 puntos de distancia del primer partido. El PP obtuvo, por primera vez en su carrera política, mayorías absolutas en 3.016 municipios españoles y triunfa en las capitales de provincia andaluzas y extremeñas, «feudos» tradicionales de la izquierda. Incrementó en más de 10 puntos su porcentaje de votos y en 8 puntos su representación municipal. Esta victoria significó un paso más en una carrera ascendente que culmina en las elecciones legislativas de 1996. De esta manera, podemos apuntar que la interrelación entre la esfera política municipal y la nacional fue relevante en estos casos. Aunque cada una de ellas mantiene sus propias especificidades, las elecciones municipales de 1995 fueron el paso decisivo para el «salto» del PP al escenario político nacional, tras el cambio de comportamiento de un importante segmento del electorado. Además, la concentración de apoyos entre los partidos nacionales - PP, PSOE e IU_ pasa de ser el 62 por 100 en 1991 a representar el 77,8 por 100 de los votos. Lógicamente, afecta a los partidos menores, quienes en mayo de 1991 habían captado un 38 por 100 de los electores y sólo logran en 1995 un 22,2 por 100 de éstos.

Si nos centramos en determinar cuál ha sido la distribución de los apoyos electorales en los municipios según los tamaños de población, aportamos algo más sobre el comportamiento en las elecciones municipales. Al ser nuestro objeto de análisis una realidad múltiple que constituye un aglomerado de orientaciones, somos conscientes de las deformaciones que pueden surgir. Además de incidir la ubicación geográfica de los municipios, que analizaremos posteriormente (no es lo mismo que analicemos los resultados electorales de un municipio de Castilla y León que los de otro en Andalucía, por poner dos ejemplos en los que las preferencias electorales son más claras), los apoyos partidistas se ven afectados por los tamaños de las circunscripciones. De hecho, la distribución de las circunscripciones electorales representa una de las cuestiones políticamente más discutidas cuando se elabora y evalúa el rendimiento de un sistema electoral (Nohlen, 1994: 47). Los índices de proporcionalidad disminuyen cuando aumenta el tamaño de los municipios; de ahí que en los resultados de las elecciones municipales la proporcionalidad de las circunscripciones con un alto número de representantes es superior al resto - como es el caso de los grandes municipios urbanos-, mientras que en los municipios menores los efectos del sistema electoral tienden a asemejarse a ciertos patrones mayoritarios de la normativa proporcional. De forma que se puede hablar de que la España local «dispone de toda una serie de distintos sistemas electorales al amparo de un sistema» (Rae, 1993: 10). 


\section{CUADRO 3}

Preferencias electorales en los comicios municipales de 1991 y 1995

\begin{tabular}{|c|c|c|c|c|}
\hline & \multicolumn{2}{|c|}{ Elecciones de 1991} & \multicolumn{2}{|c|}{ Elecciones de 1995} \\
\hline & $\%$ Votos & $\%$ Concejales & $\%$ Votos & $\%$ Concejales \\
\hline PP & 25,3 & 29,1 & 35,3 & 37,6 \\
\hline 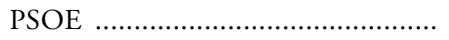 & 28,3 & 38,1 & 30,8 & 32,2 \\
\hline IU & 8,4 & 3,9 & 11,7 & 5,3 \\
\hline 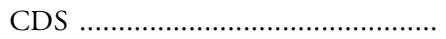 & 3,9 & 4,4 & 0,3 & 0,2 \\
\hline $\mathrm{CiU}$ & 4,8 & 6,6 & 4,4 & 6,4 \\
\hline 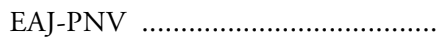 & 1,6 & 1,5 & 1,4 & 1,5 \\
\hline 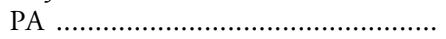 & 1,8 & 0,8 & 1,2 & 0,5 \\
\hline CC & - & - & 0,9 & 0,5 \\
\hline BNG & 0,6 & 0,4 & 0,9 & 0,6 \\
\hline ERC & 0,5 & 0,3 & 0,9 & 0,8 \\
\hline HB & 1,0 & 1,1 & 0,8 & 0,9 \\
\hline 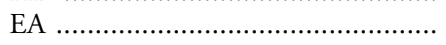 & 0,7 & 0,6 & 0,6 & 0,6 \\
\hline 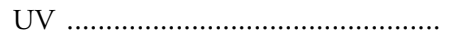 & 1,0 & 0,5 & 0,6 & 0,3 \\
\hline 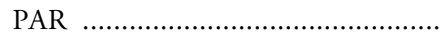 & 0,7 & 1,7 & 0,5 & 1,6 \\
\hline 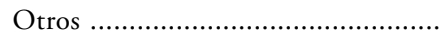 & 17,3 & 4,1 & 6,1 & 4,5 \\
\hline 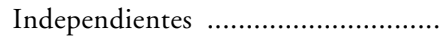 & 4,1 & 6,9 & 3,6 & 6,5 \\
\hline 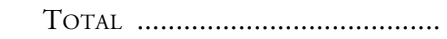 & 100,0 & 100,0 & 100,0 & 100,0 \\
\hline
\end{tabular}

FuENTE: Elaboración propia. Datos del Ministerio de Justicia e Interior.

La serie electoral segmentada por tamaño de distritos ha ofrecido una tendencia en la que se percibe una concentración de apoyos electorales del PP en municipios rurales y en urbes de más de 100.000 habitantes. Por su parte, aunque el PSOE inicialmente fue un partido apoyado en los ámbitos urbanos, ha incrementado su presencia en todo tipo de municipios después de acceder al gobierno nacional (Delgado y López Nieto, 1997: 269). Es en las convocatorias municipales de los años noventa cuando se percibe una alteración de la distribución de los apoyos electorales de los dos grandes partidos nacionales, manteniéndose una continuidad en los municipios rurales, que siguen siendo las poblaciones en las que el PP está arraigado con fuerza. Su predominio es relevante frente al resto de los partidos políticos, generando unos reducidos niveles de competitividad respecto al PSOE. El cambio se percibe en los municipios intermedios — hasta 50.000 habitantes_- si bien debemos diseccionar entre aquellos que tienen entre 251 y 5.000 habitantes y los de 5.001 hasta 50.000: dentro de los primeros, los resultados de las elecciones de 1995 muestran la estrecha competencia del PSOE con el PP al haber obtenido apoyos electorales similares; mientras, en municipios de 5.001 a 50.000 habitantes, ámbito fecundo para la implantación de la fuerza socialista, ésta se impone 
sobre el PP. Consecuentemente, el margen de competitividad electoral es alto entre ambas fuerzas, aunque los efectos distorsionantes del sistema electoral «premian» a estos dos partidos, otorgándoles a ambos una mayor representación municipal, un mayor número de concejales en relación con los votos obtenidos. En 1995, en los municipios con mayor número de habitantes —más de 50.000—, esta distribución de apoyos se altera y el PP capta a un importante segmento del electorado municipal. La distancia entre los dos primeros partidos crece, por lo que el margen de competitividad se debilita, originando sin embargo una más estrecha competitividad municipal, consecuencia de nuevo del efecto proporcional del sistema electoral.

A pesar de la presencia en todos estos distritos de un tercer partido de ámbito nacional como es IU, éste no capta un número relevante de electores en municipios pequeños dada su escasa implantación en ellos. Es en los distritos de más de 5.000 habitantes, y con mayor fuerza en los núcleos urbanos, donde sus votos inciden en la desconcentración de los apoyos entre los dos partidos nacionales mayoritarios. Si nos fijamos también en los porcentajes de votos de otras fuerzas menores, su presencia se reduce según aumenta el tamaño de población. Aunque esta tendencia ya había sido destacada para anteriores convocatorias municipales (Delgado, 1997), se acentúa más en estas elecciones, pudiendo interpretarse como un rasgo más de la nacionalización que parece caracterizar a las elecciones de 1995, en las que se reproduce con ciertas «imperfecciones» el sistema de partidos nacional.

\section{CUADRO 4}

Distribución de los apoyos electorales municipales de 1995 por tramos de población

\begin{tabular}{|c|c|c|c|c|c|c|c|c|c|c|}
\hline & \multicolumn{2}{|c|}{$T 1$} & \multicolumn{2}{|c|}{$T 2$} & \multicolumn{2}{|c|}{ T3 } & \multicolumn{2}{|c|}{ T4 } & \multicolumn{2}{|c|}{ T5 } \\
\hline & $\% V$ & $\% C$ & $\% V$ & $\% C$ & $\% V$ & $\% C$ & $\% V$ & $\% C$ & $\% V$ & $\% C$ \\
\hline PP & 43,65 & 52,49 & 33,88 & 36,84 & 30,13 & 31,29 & 31,13 & 32,97 & 38,64 & 37,70 \\
\hline PSOE …......................... & 25,19 & 22,69 & 33,67 & 33,36 & 32,47 & 34,6 & 32,47 & 35,00 & 28,87 & 31,28 \\
\hline 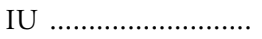 & 1,11 & 0,65 & 5,84 & 3,75 & 10,18 & 8,92 & 12,84 & 12,28 & 14,26 & 14,66 \\
\hline Independientes ........ & 5,65 & 6,66 & 6,54 & 6,85 & 5,91 & 6,23 & 3,57 & 2,98 & 0,95 & 1,20 \\
\hline $\mathrm{CiU}$ & 5,64 & 8,30 & 5,84 & 7,06 & 4,08 & 4,70 & 3,73 & 4,09 & 4,23 & 3,69 \\
\hline PNV …..................... & - & - & 1,48 & 1,62 & 1,69 & 1,78 & - & - & 1,32 & 2,05 \\
\hline PAR ......... & 4,14 & 4,60 & 1,08 & 1,59 & - & - & - & - & - & - \\
\hline BNG & - & - & - & - & 1,90 & 1,69 & - & - & - & - \\
\hline 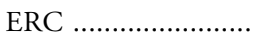 & 0,73 & 0,47 & - & - & - & - & - & - & - & - \\
\hline PA & - & - & - & - & - & - & 1,70 & 1,45 & 1,29 & 1,01 \\
\hline CC …...................... & - & - & - & - & - & - & 1,41 & 1,42 & - & - \\
\hline Otros & 4,94 & 4,12 & 10,26 & 8,88 & 10,70 & 10,70 & 11,82 & 9,80 & 9,00 & 8,37 \\
\hline
\end{tabular}

T1: Hasta 250 habitantes. T2: De 251 a 5.000 habitantes. T3: De 5.001 a 20.000 habitantes. T4: De 20.001 a 50.000 habitantes. T5: Más de 50.000 habitantes.

FUENTE: Elaboración propia. Datos del Ministerio de Justicia e Interior. 


\section{CUADRO 5}

Niveles de competitividad en las elecciones municipales de 1995

\begin{tabular}{|c|c|c|}
\hline & \multicolumn{2}{|c|}{ Competitividad electoral y municipal, 1995} \\
\hline & C.E. & C.M. \\
\hline 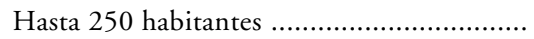 & 18,40 & 29,80 \\
\hline 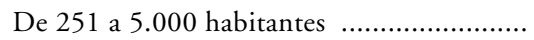 & 0,21 & 3,48 \\
\hline De 5.001 a 20.000 habitantes ........................ & 2,34 & 3,37 \\
\hline De 20.001 a 50.000 habitantes .................... & 1,84 & 2,03 \\
\hline 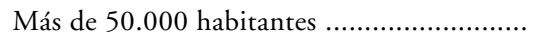 & 9,77 & 6,42 \\
\hline
\end{tabular}

C.E.: Competitividad electoral. C.M.: Competitividad municipal.

Fuente: Elaboración propia. Datos del Ministerio de Justicia e Interior.

En esta compleja realidad municipal, la fuerte presencia de partidos nacionalistas es un elemento que distorsiona la tendencia nacional del ámbito local. Las CC.AA. se configuran como escenario en el que la dimensión de la identidad nacional e ideológica explica gran parte del comportamiento electoral español, proyectándose territorialmente — de forma estable en sucesivas convocatorias electorales - en la orientación del voto (Montero y Torcal, 1990; ERA, 1997). En esta dirección también existen modelos territoriales y arenas de competición municipal diferenciadas en las que el voto se dirige a formaciones regionalistas/nacionalistas, rompiendo el patrón antagónico de las dos fuerzas mayoritarias (Delgado y López Nieto, 1992: 208). Atendiendo a esta realidad, las elecciones municipales son un escenario subnacional en el que el comportamiento configura modelos diferenciados que predominan si el ingrediente «local» prevalece. Como ya hemos destacado, la presencia de independientes en el ámbito municipal es todavía perceptible y, aunque se va difuminado, su existencia sólo es comprendida en estos ámbitos subnacionales, ya que la esfera política nacional acapara para los grandes partidos toda la competición, haciendo que estos actores políticos menores no tengan relevancia nacional. Sin embargo, no podemos olvidar que la nacionalización y la concentración de apoyos electorales en partidos de ámbito nacional afecta a la política municipal y se percibe claramente en la estructura del voto en el ámbito comunitario.

Ya desde 1991, una vez que las fuerzas de centro-derecha se implantan y articulan diversos intereses, la capacidad de integración del voto regional es una realidad en algunas CC.AA. El voto útil se solapa con rasgos nacionales y, aunque las Comunidades con fuerte tradición nacionalista canalizan el mayor número de electores a través de fuerzas regionales - como es principalmente el caso de Cataluña y País Vasco, además de Canarias-, el mapa electoral de 1995 ofrece un panorama muy parecido al escenario político nacional. El PP 
predomina en todas las CC.AA. excepto en Andalucía y Extremadura y en las dos «históricas» mencionadas anteriormente. Su presencia varía cuantitativamente de unas regiones a otras, pero en términos generales acapara más del 40 por 100 del voto en el escenario comunitario, excepto en Navarra y Cantabria. En estas dos Comunidades, la presencia de fuerzas regionales hace que el nivel de competición sea más estrecho, y la heterogeneidad de fuerzas desconcentra el voto entre los distintos partidos, atenuando el componente nacional.

En conclusión, las variables estudiadas - el tamaño de las circunscripciones y la distribución geográfica- son dos elementos con incidencia variable en las orientaciones partidistas. Aunque tengan un peso explicativo sobre los apoyos electorales municipales, están también relacionados con la dinámica política nacional. Lógicamente, las variaciones estarán ligadas a la especificidad de los procesos que se analicen (ya que la presencia de partidos menores es superior en el ámbito subnacional que en el nacional, por ejemplo); sin embargo, la interconexión de las esferas políticas parece ser una constante estructural en los análisis electorales, que se refleja con más intensidad en las elecciones municipales de 1995.

\section{CUADRO 6}

Distribución de los apoyos electorales por CC.AA. en las elecciones municipales de 1995

\begin{tabular}{|c|c|c|c|c|c|c|}
\hline CC.AA. & $P P$ & PSOE & $I U$ & Indep. & Regionalistas* & Otros \\
\hline Andalucía .................... & 31,2 & 33,9 & 18,1 & 5,7 & 2,3 & 1,9 \\
\hline Aragón . ....................... & 39,6 & 27,6 & 8,9 & 2,0 & 16,5 & 5,2 \\
\hline Asturias …...................... & 40,1 & 34,8 & 15,3 & 2,9 & - & 6,9 \\
\hline Baleares …....................... & 42,4 & 24,9 & 5,9 & - & - & 10,5 \\
\hline Canarias ........................ & 27,3 & 25,0 & 4,3 & 4,7 & 36,4 & 2,3 \\
\hline Cantabria ...................... & 33,8 & 28,1 & 7,3 & 4,3 & 23,5 & 2,9 \\
\hline Castilla-La Mancha ... & 44,9 & 39,3 & 9,2 & 2,8 & 3,0 & 0,7 \\
\hline Castilla y León ........... & 48,8 & 30,1 & 7,7 & 4,6 & 5,8 & 2,9 \\
\hline Cataluña ....................... & 12,2 & 32,9 & 11,9 & 4,3 & 36,2 & 2,3 \\
\hline Comunidad Valenciana. & 41,2 & 33,0 & 11,0 & 2,7 & 11,2 & 0,9 \\
\hline Extremadura ............... & 37,7 & 41,8 & 11,0 & 3,8 & 5,7 & 0,1 \\
\hline Galicia ......................... & 47,9 & 26,7 & 2,8 & 6,5 & 13,1 & 3,0 \\
\hline Madrid ......................... & 47,5 & 28,6 & 17,4 & 2,8 & - & 3,6 \\
\hline Murcia ......................... & 50,0 & 31,8 & 11,9 & 3,4 & 2,2 & 0,6 \\
\hline Navarra ......................... & 26,7 & 19,2 & 7,5 & 16,6 & 21,2 & 16,2 \\
\hline País Vasco ..................... & 14,4 & 16,8 & 7,3 & 1,7 & 59,6 & 0,2 \\
\hline Rioja .............................. & 47,2 & 34,4 & 5,7 & - & - & 7,2 \\
\hline
\end{tabular}

* En Andalucía, PAP; en Aragón, PA; en Canarias, CC (26,6 por 100); en Cantabria, UPC (13 por 100); en Cataluña, CiU (30,1 por 100$)$, ERC (6,25 por 100); en Galicia, BNG; en Navarra, HB (8,5 por 100), EA (5,2 por 100); en la Comunidad Valenciana, UV (5,5 por 100), UPV (3,5 por 100); y en el País Vasco, PNV (27,8 por 100$)$, HB (14,3 por 100$)$, EA (10,6 por 100). El resto son otros partidos regionales.

Fuente: Elaboración propia. Datos del Ministerio de Justicia e Interior. 


\section{EL COMPORTAMIENTO ELECTORAL EN LAS ELECCIONES MUNICIPALES DE 1995: UNA APROXIMACIÓN}

De los análisis agregados anteriores hemos ido extrayendo algunas conclusiones que nos permitían identificar un componente "específico" no local que había guiado las directrices de las elecciones municipales de 1995. Sin embargo, la tradición metodológica agregada debe tomar en consideración a la hora de explicar el comportamiento electoral otros factores como los socioestructurales y los de contenido más político. Lo que aquí pretendemos es explorar la otra cara del comportamiento electoral, lograr identificar los elementos que han influido en la decisión electoral y que han afectado, por tanto, a los resultados de la convocatoria de 1995 . Una vez que se han estudiado las declaraciones expresas de los electores a través de la encuesta postelectoral del Centro de Investigaciones Sociológicas (CIS $)^{10}$, optamos por centrarnos en dos aspectos que consideramos relevantes en estas elecciones: por un lado, estudiar el flujo de transferencias, captaciones y pérdidas de electores de los principales partidos nacionales; $y$, por otro lado, mediante una serie de análisis de correlación y regresión múltiple, explorar cuáles han sido las variables determinantes que han incidido en las orientaciones de los electores. Se trata de explicar el voto al PP y al PSOE mediante una serie de variables básicas, consistentes en diversos indicadores de carácter social y político, pretendiendo identificar la relevancia y el peso específico que tuvieron en los votantes.

\section{Transferencias y captaciones de voto entre los partidos politicos}

A primera vista y según la opinión de los electores, la situación política del país parece no haber sido un elemento influyente a la hora de votar en las elecciones municipales de $1995^{11}$. Sin embargo, las transferencias de voto entre las elecciones de 1995 y las anteriores elecciones municipales muestran las alteraciones de una importante dimensión de las preferencias partidistas de los electores, un significativo número de los cuales cambió la orientación de su voto, contribuyendo a una nueva distribución de la fuerza electoral de los principales partidos.

Centrándonos en primer lugar en la tasa de lealtad de los electores municipales, es el PP quien en mayor medida tiene votantes fieles: el 93,1 por 100 de la composición electoral en 1995 corresponde a quienes también optaron por

${ }^{10}$ Los datos que a partir de este momento se presentan provienen del estudio postelectoral n. ${ }^{\circ} 2183$, realizado por el CIS en junio de 1995 a una muestra de 6.510 individuos de ambos sexos y mayores de edad.

${ }_{11}$ Para el 57 por 100 de los entrevistados influyó poco y nada el contexto político, aunque deberíamos resaltar que para un 39,5 por 100 tuvo cierta relevancia. Un significativo porcentaje de entrevistados considera que a la hora de votar ha influido en mayor medida el candidato — para el 46,5 por 100 — frente a la situación política — para el 42,6 por 100—. Son cifras muy similares, por lo que ahondaremos más en esta cuestión una vez que nos centremos en la orientación del voto entre los dos partidos mayoritarios. 
este partido en las elecciones municipales anteriores. Su grado de captación es, por tanto, el más reducido de todos los partidos y el grado de transferencia de sus electores hacia otros partidos es el menor, incidiendo lógicamente en un reforzamiento de sus apoyos municipales. Quien experimenta las mayores pérdidas electorales es el PSOE, ya que el 27,8 por 100 de sus votantes de las elecciones de 1991 decide en 1995 transferir su voto a otras formaciones políticas: el más beneficiado es el PP, quien atrae al 13,6 por 100 ; el 8,6 por 100 es captado por IU y el resto se reparte entre otras fuerzas regionales y partidos menores. Sin embargo, no todo parecen ser pérdidas ya que el PSOE también logra captar al 6,5 por 100 de votantes comunistas, al 13,5 por 100 de votantes del CDS y a un mínimo porcentaje de votantes populares. Sin embargo, la escasa representación del partido centrista - CDS - beneficia mayoritariamente al PP, quien atrae a más de la mitad de estos electores. Paradójicamente, IU cede un 5,5 por 100 de los apoyos de 1991 al PP, siendo esta proporción incluso mayor que la que se reparten las fuerzas subnacionales. Entre ellas, destacar un significativo flujo de votantes de independientes al PP, a otros partidos subnacionales, a IU y, en menor cantidad, al PSOE. El mismo comportamiento se observa entre los votantes de otros partidos menores, entre los cuales es mayor la captación de votantes que alcanza el PP y son los partidos políticos con los apoyos más fluctuantes. El voto blanco de 1991, sin embargo, es atraído en mayores dosis por IU y por PP. En definitiva, la disgregación de las bases electorales del PSOE, del CDS y de las formaciones políticas menores beneficia al PP y muestra una concentración del voto en los partidos políticos de ámbito nacional.

\section{CUADRO 7}

Transferencias y captaciones de voto en las elecciones municipales de 1995 por los principales partidos politicos

\begin{tabular}{|c|c|c|c|c|c|c|c|c|c|}
\hline \multirow{2}{*}{$\begin{array}{c}\text { Voto elecciones } \\
\text { municipales } 1995\end{array}$} & \multicolumn{9}{|c|}{ Recuerdo de voto en las elecciones municipales de 1991} \\
\hline & $P P$ & PSOE & $I U$ & $C D S$ & $\mathrm{CiU}$ & $P N V$ & Indep. & Otros & Blanco \\
\hline PP . & 93,1 & 13,6 & 5,5 & 51,4 & 4,0 & 1,8 & 15,4 & 22,4 & 30,8 \\
\hline PSOE & 1,9 & 72,2 & 6,5 & 13,5 & 2,3 & - & 3,8 & 4,1 & 23,1 \\
\hline IU $\ldots . . .$. & 1,9 & 8,6 & 82,4 & 5,4 & 1,2 & 3,6 & 7,7 & 9,5 & 38,5 \\
\hline $\mathrm{CiU} \ldots \ldots . . .$. & 0,1 & 0,6 & 1,6 & - & 86,1 & - & - & 1,4 & - \\
\hline PNV. & - & - & - & - & - & 92,9 & - & 0,3 & 7,7 \\
\hline Independientes . & 0,4 & 1,5 & 1,0 & 18,9 & 6,4 & - & 57,7 & 8,5 & - \\
\hline 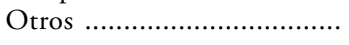 & 2,6 & 3,6 & 2,9 & 10,8 & - & 1,8 & 15,4 & 53,7 & - \\
\hline TOTAL . & 100,0 & 100,0 & 100,0 & 100,0 & 100,0 & 100,0 & 100,0 & 100,0 & 100,0 \\
\hline$(\mathrm{N})$ & 834 & 1.560 & 307 & 37 & 173 & 56 & 26 & 294 & 13 \\
\hline
\end{tabular}

FuENTE: Base de Datos del CIS. Elaboración propia. 
Estas transferencias entre los partidos políticos han de interpretarse con precaución. El comportamiento electoral de la convocatoria municipal de 1991 estaba en estrecha conexión con el tamaño del municipio. Aunque en aquella ocasión la orientación de los apoyos electorales urbanos atendió también a variables de tipo coyuntural, el triunfo del PP en un gran número de capitales de provincia y el aumento de la participación urbana mostraban ya los primeros indicios del cambio que se produjo definitivamente en la convocatoria electoral de 1995. El PP logra mantener un amplio margen de fidelidad electoral en todas las circunscripciones, atrayendo en poblaciones intermedias a un elevado porcentaje de votantes socialistas. Supuso, como ya hemos apuntado anteriormente, una victoria por cuanto esta formación adolecía de representación en estas circunscripciones, acaparadas de forma estructural por los socialistas, de manera que esta captación favoreció, y en buena parte determinó, su triunfo electoral. Lo que sí es cierto es que la reducción de los apoyos electorales socialistas en 1995 afectó de forma específica a la dinámica política municipal y traspasó esta esfera, incidiendo también en la política nacional. Así, entre ambas elecciones municipales tuvieron lugar las elecciones legislativas de 1993, en las que se modificaron también los apoyos electorales de los partidos mayoritarios teniendo como consecuencia, por primera vez en la etapa democrática española, un gobierno de apoyos que asegurase una gobernabilidad, al no revalidar el PSOE la mayoría absoluta de la que había gozado hasta entonces.

Pero si existió un ingrediente nacional en las elecciones municipales de 1995, sería bueno dirigir una mirada hacia el comportamiento en las legislativas de 1993 y contrastar ambas convocatorias con el propósito de delimitar las tendencias partidistas. Si bien sabemos que son dos convocatorias distintas, una correspondería a elecciones de primer orden y la otra a elecciones de segundo orden, permitiría perfilar la continuidad o discontinuidad de las preferencias partidistas y ahondar más en las orientaciones de los votantes, toda vez que en la arena de primer orden los resultados de las elecciones legislativas convocadas en los años noventa han tenido consecuencias muy importantes para el sistema político español. Tanto las elecciones de 1993 como las elecciones de 1996 han significado un cambio en la reciente historia de nuestro sistema de partidos. En la primera convocatoria, el modelo de partido hegemónico generado desde las elecciones de 1982, y que se había mantenido durante un período de once años, desaparece. Se inaugura una nueva etapa en la que el sistema de partidos adquiere una configuración morfológica cercana a aquella del pluralismo moderado que caracterizó el período de 1977-1982, si bien con un componente de bipartidismo más acentuado. Las elecciones legislativas de 1993 registraron un alto nivel de movilización, en relación a la tendencia de años anteriores. Las encuestas electorales reflejaban un avance progresivo de la intención de voto del PP y un descenso del voto del PSOE, dando una estrecha ventaja a los populares, que ya habían sido los vencedores en las elecciones municipales de 1995. La posibilidad de 
una alternancia política sirvió de motivo para movilizar al electorado. El adelanto de la convocatoria electoral de 1993, el clima político que reinaba y los resultados que predecían las encuestas confirmaron un alto nivel de competitividad entre las dos fuerzas políticas mayoritarias, reflejado ya en el escenario subnacional. La expansión del voto del PP que se inicia en 1993 corre paralela al lento retroceso del PSOE en aquellas elecciones legislativas. Este progresivo debilitamiento de los socialistas ya había quedado patente en las convocatorias electorales de segundo orden de los años noventa: en primer lugar, como ya hemos reflejado, las elecciones municipales de 1991 supusieron una modificación de las preferencias partidistas de las zonas urbanas; posteriormente, las elecciones europeas iniciaron el cambio del modelo partidista al otorgar la victoria nacional al PP, que en 1995 se confirma de nuevo como partido vencedor en las elecciones municipales y autonómicas de ese mismo año.

En este clima las transferencias de voto entre el electorado de 1993 y 1995 , concretamente entre los dos partidos mayoritarios, despunta ya los resultados mencionados. Condicionados por el clima político, los convocados a participar en 1995 tuvieron la posibilidad de evaluar la gestión política del PSOE en la arena nacional, ante lo cual este partido pierde un 12,6 por 100 de sus votantes, que se adhieren a las bases electorales del PP. El otro segmento que se inclina por este partido son aquellos ciudadanos que por primera vez acceden a su derecho político: el 36,5 por 100 de los jóvenes votantes que votan por vez primera tiende a incrementar el componente electoral de los populares. Sin embargo, el PSOE también capta en las elecciones municipales de 1995 a un relevante grupo de ciudadanos que en la convocatoria legislativa vota en blanco y atrae a un 8,4 por 100 de votantes de IU que en 1995 transfieren su apoyo a los socialistas. Y, siguiendo esta lógica, también capta a una parte de electores del CDS en las generales de 1993. De esta forma, el balance que se desprende de los flujos entre estas dos elecciones —que, recordemos, son de una naturaleza muy distinta aunque la interpretación de ambas refleje cierta interconexión - muestra un elevado movimiento que afecta a la composición electoral de las principales fuerzas políticas. 


\section{CUADRO 8}

Transferencias y captaciones de voto en las elecciones municipales de 1995 y las elecciones legislativas de 1993

Recuerdo de voto en las elecciones generales de 1993

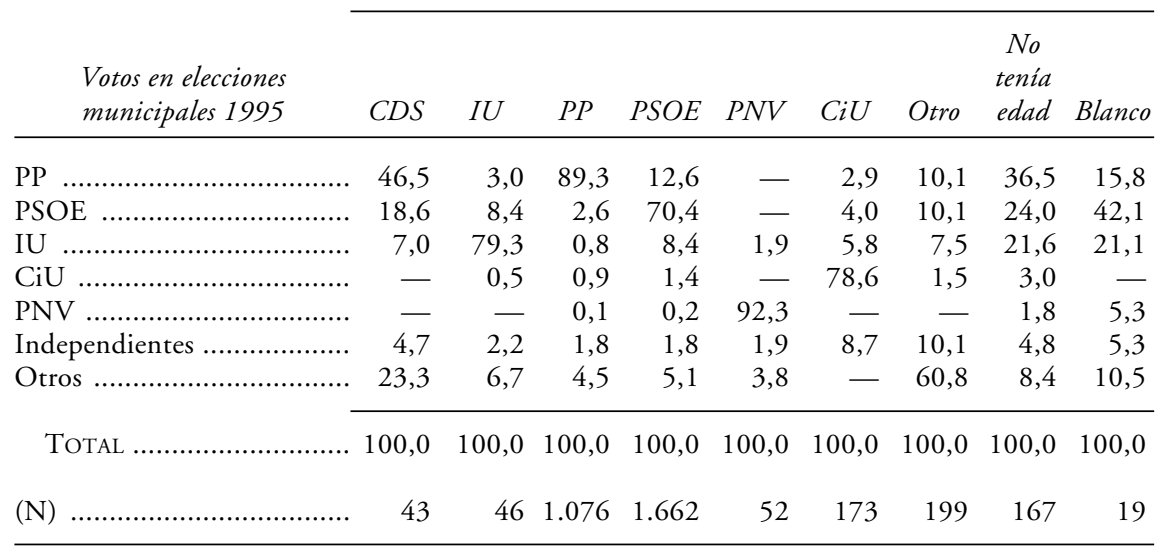

FueNTE: Base de Datos del CIS. Elaboración propia.

\section{El voto municipal del PP y el PSOE en 1995}

La elevada competición entre el PP y el PSOE en las elecciones municipales de 1995 originó unos resultados que alteraban la dinámica política municipal. Aunque las transferencias de votantes del PSOE se realizaron tanto hacia el PP como hacia IU, el importante incremento de las bases populares obliga a detenernos en investigar cuáles fueron los motivos que incidieron en los votantes del PP y los votantes del PSOE para apoyar a estos partidos. La mayoría de los estudios sobre comportamiento electoral muestran que las dos principales variables que influyen en el voto son el liderazgo y la ideología, dejando en un segundo plano otros cleavages presentes en la sociedad (Gunther, 1991; Justel, 1991; Gunther y Montero, 1994). Sin embargo, recientemente se ha percibido el vínculo existente entre los conflictos sociales y los partidos políticos, por lo que la clase social parece emerger como variable determinante de las preferencias electorales entre los dos partidos mayoritarios (Torcal y Chibber, 1995). A pesar de todo ello, nuestro escenario de actuación se circunscribe a unas características muy específicas y está dominado por unos condicionantes coyunturales. Realmente, el tratar de verificar estas cuestiones, sin duda de gran interés, está lejos de nuestros propósitos. El cometido que nos mueve ahora es tratar de identificar mediante un análisis de regresión múltiple cuáles han sido los factores predominantes en las preferencias electorales municipales 
hacia los dos principales actores políticos ${ }^{12}$. Previamente es necesario realizar una aclaración metodológica. Dado que las relaciones causales entre las variables son complejas, nos hemos limitado a considerarlas a todas ellas como variables independientes, distinguiendo únicamente entre variables de contenido político-actitudinal y otras meramente socioestructurales. Una vez estudiadas ambas optamos por excluir del análisis estas últimas por un criterio de mejora y validez externa del modelo ${ }^{13}$. La escasa proporción de varianza que explicaban estas variables podría estar en conexión con la especificidad de estas elecciones municipales, en las que predominaron elementos políticos. Además, aunque la relevancia secundaria de los factores sociológicos se ha demostrado sobradamente (Crewe, 1977; Inglehart, 1986), nos confirma que éstos se postergan a un segundo plano, máxime cuando se incluyen factores políticos altamente correlacionados con una variable dependiente de tipo político como es la nuestra.

Una vez realizada esta aclaración, al comparar los factores que incidieron en la orientación del voto municipal entre ambos partidos, el rasgo que destaca a primera vista es que todas las variables políticas correlacionan en mayor medida con el voto al PP, siendo menores estos índices en el voto socialista. Lógicamente, el peso del candidato electoral y de la situación política del país influyen de forma inversa entre ambos partidos. Así, para una proporción de votantes del PP, el momento político en el que se ubican estas elecciones fue más determinante que la propia figura del candidato municipal. En el votante popular predominó la idea de que el PP ganase las elecciones por encima de otras cuestiones político-ideológicas. Frente a esta actitud, el apoyo electoral hacia el PSOE estuvo mediado por las clásicas cuestiones de cercanía al partido y por una trayectoria de lealtad electoral.

12 En este análisis la variable dependiente es el voto declarado al PP y al PSOE, respectivamente, y las variables independientes están constituidas por diversos indicadores sociales y políticos.

${ }^{13}$ Optamos por no incluir en el texto los datos de las correlaciones entre el voto a los partidos en las elecciones municipales y las variables socioestructurales (sexo, edad, situación laboral, nivel de estudios y tamaño de hábitat), dada la escasa información que aportan a nuestro objeto de estudio. Tan sólo apuntar que ni siquiera la distribución sociolaboral — trabaja, jubilado, parado, estudiante o sus labores - estaba estrechamente asociada con la orientación del voto hacia estas dos formaciones políticas. 


\section{CUADRO 9}

Coeficientes de correlación simple entre el voto al PP y al PSOE y variables independientes de carácter político

\begin{tabular}{|c|c|c|}
\hline & Voto al PP & Voto al PSOE \\
\hline Imagen PP/PSOE en la campaña electoral . & 0,436 & 0,398 \\
\hline Grado de interés en la campaña electoral .... & 0,132 & 0,015 \\
\hline Movilización: situación política del país ............................... & 0,212 & $-0,203$ \\
\hline 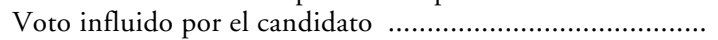 & $-0,117$ & 0,201 \\
\hline Voto influido por la situación política del país .................... & 0,135 & $-0,189$ \\
\hline Preocupación por una victoria amplia del PP ...................... & - & 0,246 \\
\hline Voto de castigo al PSOE & 0,272 & - \\
\hline Voto: PP ganase las elecciones & 0,719 & - \\
\hline 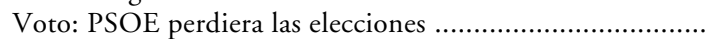 & 0,457 & - \\
\hline 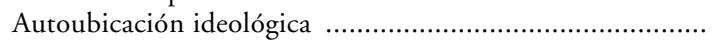 & 0,550 & 0,572 \\
\hline Cercanía PP/PSOE & 0,673 & 0,452 \\
\hline Valoración líderes nacionales (Aznar/González) ................. & 0,587 & 0,449 \\
\hline 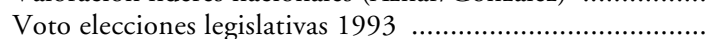 & 0,663 & 0,574 \\
\hline 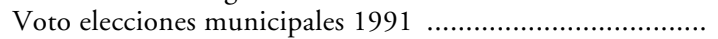 & 0,612 & 0,577 \\
\hline
\end{tabular}

FueNTE: Base de Datos del CIS. Elaboración propia.

El análisis de regresión "paso a paso" nos permite confeccionar los dos modelos explicativos de voto, dando entrada únicamente a aquellas variables con cierto poder explicativo sobre la orientación electoral, dejando el resto de ellas fuera del estudio. Al realizar una primera comparación entre ambos modelos de voto, la diferencia entre ellos radica en la desigual proporción de varianza explicada en los dos $\operatorname{casos}^{14}$ : el 65 por 100 del voto al PP en estas elecciones municipales es explicado por siete variables de tipo político, frente a ocho variables que en el caso del PSOE explican un porcentaje menor, el 48 por 100 de la varianza total. En síntesis se desprende que la fuerza explicativa de elementos políticos es mayor en la orientación popular, con un menor número de elementos integrantes. De hecho, si nos detenemos en la composición de las variables para uno y otro caso podemos apreciar diferencias significativas. Para los votantes socialistas parece haber sido determinante haber apoyado a esta formación en las elecciones legislativas de 1993; de ahí que este partido mantenga principalmente a votantes leales, que se sienten cercanos a esta formación y que, además, la han votado en las elecciones municipales de 1991. Paradójicamente, la situación política por la que atravesaba el país en 1995 ha jugado a favor del voto socialista, a lo que se une la preocupación porque el PP lograra una victoria con amplia mayoría. Podría equivaler, tal y

${ }^{14}$ Las cifras expresan las medidas de porcentaje de varianza explicada por cada variable o grupo de variables, e indican la propensión a votar a un partido concreto. 
como parece que ocurrió en las elecciones legislativas precedentes, a un comportamiento de indecisión que finalmente se convierte en apoyo al Partido Socialista ${ }^{15}$. La imagen del PSOE en la campaña electoral también tiene cierta influencia en la decisión electoral y se configura como un componente más neutralizador de las tendencias nacionales. Los dirigentes socialistas intentaron intervenir en la campaña electoral con un discurso orientado mayoritariamente a destacar los aspectos locales y a personalizar a los candidatos. Se pretende resaltar la gestión realizada por los alcaldes socialistas con el fin de reforzar la dimensión municipal y como forma de desvincular los aspectos nacionales que atentaban contra la imagen del Partido Socialista. Esta estrategia funcionó en dos municipios urbanos, en Barcelona y en La Coruña, donde los candidatos socialistas — Maragall y Vázquez — fueron reelegidos a pesar de los condicionantes nacionales presentes en el ambiente político. Junto a todos estos ingredientes, la influencia del candidato nacional, esto es, la valoración positiva que mantienen hacia Felipe González, cerraría el bloque de variables que tuvieron un significado específico entre los votantes que apoyaron a este partido.

La lealtad partidista y el sentimiento de cercanía al partido parecen configurarse con fuerza y convertirse en variables influyentes a la hora de determinar la orientación del voto en estas elecciones municipales, ya que también son determinantes - y en mayor medida - para los electores que votaron al PP en las pasadas elecciones municipales. Sin embargo, en el voto al PP la variable explicativa que se presenta con arraigo en la orientación partidista está relacionada con la necesidad de que este partido gane (parece que a toda costa) las elecciones municipales. A pesar de que la relevancia del factor ideológico que se percibe con claridad en las elecciones legislativas (Montero, 1996: 213) no ha tenido la incidencia esperada en estas elecciones subnacionales, a excepción de la tímida incursión que se aprecia en el modelo del voto popular, no contribuye demasiado a su explicación. Más bien el anclaje psicológico, mediante la cercanía al partido o identificación partidista, ha actuado como mecanismo sustitutivo.

El liderazgo ocupa una posición relevante entre la serie de factores explicativos de la decisión electoral en el voto al PP. El líder nacional se ubica en una posición predominante que coincidiría con el ingrediente de voto de castigo al PSOE, entre cuyos votantes la valoración de Felipe González aporta poco en la orientación electoral. Este factor de castigo al partido del gobierno nacional se convierte en un elemento que confirma el componente de nacionalización latente en estas elecciones municipales. Si el elector se hubiera movilizado por cuestiones específicamente locales, el liderazgo municipal sería una variable con peso en la decisión electoral. Sin embargo, no fue así. Entre los tradiciona-

15 Este comportamiento puede asemejarse al que se produjo en el período previo a las elecciones legislativas de 1993. El alto componente de «indecisos» obstaculizó las predicciones electorales y los resultados derivados de los sondeos de opinión. 


\section{CUADRO 10}

Modelo de explicación del voto al PP y al PSOE en las elecciones municipales de 1995

\begin{tabular}{|c|c|c|c|}
\hline $\begin{array}{c}\text { Variable } \\
\text { dependiente }\end{array}$ & $\begin{array}{c}\text { Proporción } \\
\text { varianza } \\
\text { explicada }\left(R^{2}\right)\end{array}$ & Variables explicativas & $\begin{array}{c}\text { Proporción } \\
\text { acumulada } \\
\text { de varianza } \\
\text { explicada }\left(R^{2}\right)\end{array}$ \\
\hline Voto PP & 0,65 & $\begin{array}{l}\text { PP ganase las elecciones } \\
\text { Cercanía al PP } \\
\text { Voto PP municipales } 1991 \\
\text { Valoración José M. }^{\text {a Aznar }} \\
\text { Voto castigo al PSOE } \\
\text { Imagen PP en la campaña } \\
\text { Autoubicación ideológica }\end{array}$ & $\begin{array}{l}0,60 \\
0,63 \\
0,64 \\
0,65 \\
0,65 \\
0,65 \\
0,65\end{array}$ \\
\hline Voto PSOE & 0,48 & $\begin{array}{l}\text { Voto PSOE en legislativas } 1993 \\
\text { Cercanía PSOE } \\
\text { Voto PSOE municipales } 1991 \\
\text { Situación política general } \\
\text { Preocupación victoria amplia PP } \\
\text { Imagen PSOE en la campaña } \\
\text { Movilización: situación política } \\
\text { Valoración Felipe González }\end{array}$ & $\begin{array}{l}0,33 \\
0,42 \\
0,45 \\
0,46 \\
0,47 \\
0,48 \\
0,48 \\
0,48\end{array}$ \\
\hline
\end{tabular}

Fuente: Base de Datos del CIS. Elaboración propia.

les factores políticos que ayudan a entender cómo y por qué votan los electores se han entremezclado cuestiones específicamente coyunturales que afectaron en los resultados de la convocatoria municipal. Cabe concluir que las claves del comportamiento electoral de 1995 pueden radicar en la posibilidad que tuvieron electores de modificar el panorama político, optando por un voto de castigo al PSOE, además de la división sustancial del voto de la izquierda entre el PSOE e IU. La ayuda de estos modelos multivariables ha sido útil para corroborar la incidencia de diversos factores políticos, sin perjuicio de que posteriores desarrollos más complejos aporten nuevas perspectivas analíticas.

\section{OBSERVACIONES FINALES}

El trabajo empírico nunca es suficiente y, en nuestro caso, queda desbordado por la complejidad y la heterogeneidad de la realidad municipal española. En las elecciones municipales de 1995 se perciben elementos de nacionalización tanto por parte de los actores políticos como por los electores, que si 
bien parecían detectarse tímidamente en las elecciones municipales de 1991, aparecen con predominio en esta última convocatoria municipal. Se supera la naturaleza municipal de estos comicios y el electorado, a través de ellos, emite un juicio sobre la actuación de la institución local en función del partido del gobierno teniendo como punto de referencia la situación nacional (Rallings y Thrasher, 1993: 374). A simple vista, a estas elecciones se les puede conferir el carácter de primarias: al haber sido elecciones de evaluación de la gestión del gobierno nacional y haber supuesto un voto de castigo de grandes repercusiones para el partido del gobierno nacional. Además, su ubicación en el calendario electoral ha sido un elemento determinante al estar situadas a medio camino entre elecciones de primer orden con rasgos específicos. La movilización y los resultados electorales han sido dos indicadores utilizados que muestran un cambio progresivo, en la dirección de las orientaciones partidistas y en la concentración de los apoyos en los partidos de ámbito nacional. La tímida presencia de partidos subnacionales — nacionalistas, regionalistas e independientesno hace sino recordarnos que se trata de comicios de segundo orden en los que las especificidades de las arenas electorales sobreviven y configuran una multiplicidad de sistemas de partidos y gobiernos locales.

Las variables sociales han influido muy poco en la decisión o explicación del voto municipal de 1995. Se ha comprobado que su poder explicativo es insignificante desde el punto de vista puramente estadístico. Han predominado los factores estrictamente políticos, y ni siquiera la lealtad partidista ha permitido unos resultados satisfactorios para el partido perdedor. Muy al contrario, las transferencias de votantes entre los partidos políticos que competían en la arena municipal dieron la victoria al PP, quien logra, junto con IU - por muy distintas razones-, captar un alto porcentaje de electores socialistas descontentos y afectados por la situación de "crisis política» que se vivía en el escenario nacional. En síntesis, los factores de índole nacional se imponen sobre los locales, reduciendo la naturaleza y el significado principal de las elecciones municipales (Capo, 1991). Pero la relación de la esfera local con el ámbito nacional puede tener una doble interpretación, ya que, por otra parte, las directrices nacionales sólo explican una proporción de los resultados. La existencia de tendencias de ámbitos nacional no excluye rasgos $\mathrm{ni}$ variaciones locales. El tema de las influencias nacionales frente a las municipales no es necesariamente una cuestión excluyente; puede ser una combinación de ambas. Aunque las elecciones municipales de 1995 se interpreten con un alto contenido de elementos nacionales, lo que las confiere el carácter de elecciones «críticas» de segundo orden - por su naturaleza predictiva sobre las elecciones de la primera arena política de 1996 (Reif, 1985: 13)—, de sus resultados se traduce una línea de comportamiento nacional en el que se mezclan algunos ingredientes municipales. No puede ignorarse la importancia y el efecto de ciertos elementos subnacionales, obligando a dejar abiertas muchas cuestiones que no pueden tratarse desde una perspectiva global, sino que deben analizarse desde una visión «micro», lo que hace aconsejable acometer 
con prudencia la interpretación de estos resultados cuando se pone en tela de juicio el comportamiento en 8.000 municipios muy diferentes entre sí. Sería de sumo interés confirmar el comportamiento de los electores municipales de 1995 a través de la siguiente convocatoria municipal, de forma que se integren en la serie electoral estos resultados. Nos permitirá hacer una interpretación de la interconexión entre las esferas políticas, además de abrir nuevas perspectivas analíticas sobre la compleja naturaleza que rige en estas elecciones subnacionales.

\section{BIBLIOGRAFÍA}

Botella, J. (1992): «La galaxia local en el sistema político español», en Revista de Estudios Políti$\cos$, n. ${ }^{\circ} 76$, pp. $145-160$.

BRugué, Q., y GomÁ, R. (1998): "Gobierno local: de la nacionalización al localismo y de la regerencialización a la repolitización», en Q. Brugué y R. Gomá (coords.), Gobiernos locales y políticas públicas, Barcelona: Ariel, pp. 15-23.

Butler, D., y STOKeS, D. (1974): Political changes in Britain, Londres: MacMillan.

CAPO, J. (1991): «Elecciones municipales, pero no locales», en REIS, n. ${ }^{\circ}$ 56, pp. 143-164.

CARAMANI, D. (1994): «The territorial dimension of party change: the theory of the nationalization of politics revisited", paper presentado en el ECPR, Joint Sessions, Madrid.

Carrillo, E. (1989): "La nacionalización de la política local», en Política y Sociedad, n. ${ }^{\circ} 3$, pp. 29-46.

Corbetta, P., y PARISI, A. (1985): «La specifità del voto amministrativo: linne interpretative a partire dalle vincende degli anni settanta», en G. Martinotti (ed.), Politica locale e politiche pubbliche, Milán: Franco Agneli.

CREWE, I. (1977): «Partisan deaglinment in Britain, 1964-1974», en British Journal of Political Science, n. ${ }^{\circ}$, pp. 129-190.

Curtice, J., y Payne, C. (1991): «Local elections as national referendums in Great Britain», en Electoral Studies, vol. 10, n. ${ }^{\circ}$ 1, pp. 3-17.

Delgado, I. (1996): «Aproximación al comportamiento electoral municipal español: en busca de un modelo analítico», Tesis Doctoral, Madrid: UNED.

- (1997): El comportamiento electoral municipal español, 1979-1995, Madrid: Centro de Investigaciones Sociológicas.

Delgado, I., y López Nieto, L. (1992): «Un análisis de las elecciones municipales (Contribución a partir del caso español)", en Revista de Estudios Políticos, n. ${ }^{\circ}$ 76, pp. 195-219.

- (1997): «Las especificidades de las arenas electorales municipales», en C. Alba y F. Vanaclocha (eds.), El sistema politico local: un nuevo escenario de gobierno, Madrid: BOE-Universidad Carlos III, pp. 247-274.

DesCHOWER, C. (1994): «Local elections in Belgium: between nationalization and localism», en L. López Nieto (ed.), Local elections in Europe, Barcelona: ICPS, pp. 45-58.

EQUiPO DE RENDIMIENTO AutONÓMICO (1997): España, 1996, Madrid: Fundación Encuentros.

GAME, C. (1981): «Local elections», en Local Government Studies, vol. 7, n. o 2, pp. 63-68.

GUNTHER, R. (1991): The dynamics of electoral competition in a modern society: models of Spanish voting behavior, 1979 and 1982, Working Paper n. ${ }^{\circ}$ 28, Barcelona: ICPS.

Gunther, R., y Montero, J. R. (1994): «Los anclajes del partidismo: un análisis comparado del comportamiento electoral en cuatro democracias del Sur de Europa», en P. del Castillo (ed.), Comportamiento politico y electoral, Madrid: CIS, pp. 467-548.

GyForD, J. (1980): "Political parties and central-local relations», en G. W. Jones (comp.), New approaches to the study of central-local government relations, Londres: Sage, pp. 28-38. 
Gyford, J.; LeACHe, S., y Game, C. (eds.) (1989): The changing politics of local government, Londres: Allen \& Unwin.

INGLEHART, R. (1986): "The changing structure of polical cleavages in Western society», en R. Dalton, P. Allen y S. Flanagan (eds.), Electoral change in advanced industrial democracies, Princeton: Princeton University Press, pp. 25-69.

Justel, M. (1991): El líder como factor de explicación del voto, Working Paper n. ${ }^{\circ}$ 51, Barcelona: ICPS.

Karning, A., y Walter, B. O. (1983): «Decline in municipal turnout: a function of changing strucutre?», en American Political Quarterly, n. ${ }^{\circ} 11$, pp. 491-506.

Milbrath, L. (1965): Political participation: how and why do people get involved in politics?, Chicago: Rand McNally.

Milbrath, L. (1981): «Political participation», en S. L. Long (comp.), The handbook of political behavior, Nueva York: Plenum Press, pp. 197-239.

MONTERO, J. R. (1996): «Elecciones y comportamiento electoral: dimensiones, factores y reglas», en J. Tussell et al. (eds.), Entre dos siglos. Reflexiones sobre la democracia española, Madrid: Alianza, pp. 181-226.

Montero, J. R., y Torcal, M. (1990): «Autonomías y Comunidades Autónomas en España: preferencias, dimensiones y orientaciones políticas», en Revista de Estudios Políticos, n. ${ }^{\circ}$ 70, pp. 33-91.

Nohlen, D. (1994): Sistemas electorales y partidos políticos, México: Fondo de Cultura Económica.

Pallarés, F. (1996): "Balance de las elecciones locales en 1995», en T. Font (dir.), Anuario del Gobierno local, 1996, Madrid: Marcial Pons, pp. 149-183.

RAE, D. (1993): «El plan español en una perspectiva comparada«, en D. Rae y V. Ramírez, El sistema electoral español. Quince años de experiencia, Madrid: McGraw-Hill.

RALlingS, C., y Thrasher, M. (1993): «Exploring uniformity and variability in local electoral outcomes: some evidence from English local elections, 1985-1990», en Electoral Studies,

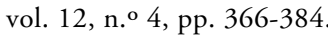

REIF, K. (1985): «Ten second-order national elections», en K. Reif (ed.), Ten European elections, Aldershot: Gower, pp. 1-36.

STEWART, J. (1983): Local government: the conditions of local choice, Londres: George Allen \& Unwin.

Thomsen, S. R. (1992): «National impact on local elections: blowing the wind?», en P. Gundelach y K. Siune (eds.), From voters to participants, Essais in honour of Ole Borre, Arhus: Politica, pp. 61-74.

Torcal, M., y Chibber, P. (1995): «Élites, cleavages y sistema de partidos en una democracia consolidada: España (1986-1992)», en REIS, n. ${ }^{\circ}$ 69, pp. 7-38.

VALLES, J. M. a y SÁNCHEZ, J. (1994): «Las elecciones municipales en España entre 1979 y 1991: balance provisional», en P. del Castillo (ed.), Comportamiento político y electoral, Madrid: CIS, pp. 365-384.

Wilson, D., y GAME, C. (1994): Local Government in United Kingdom, Londres: McMillan. 


\section{ABSTRACT}

This paper sets out to take stock of the 1995 municipal elections by examining its main elements from two analytical perspectives. The author begins with an aggregate analysis which explores levels of mobilisation, the orientation of the municipal vote and voters' preferences. She goes on to use multivariate techniques to determine the elements which most influence the voting options concerning the two biggest parties. The nationalisation of the municipal elections and the influence wielded by political parties are elements which confirm the hypothesis of the particularity of these municipal elections with a high "primary-election» content. This conditions the results, which are also inevitably influenced by their whereabouts in the election calendar, the national climate of political discontent and the possibilities of different parties taking turn in office. 